\title{
Hugh Burkhart
}

\section{Journalism resources online}

\section{From advocacy to social media}

J ournalism has changed rapidly with the advent of digital media, with traditional print outlets now operating on multiple platforms in a way that is anything but static. The core tenets of truthfulness, accuracy, and objectivity remain at the heart of the profession. ${ }^{1}$ Nevertheless, with so many outlets available for reporting the news, and with the very concept of "news" encompassing everything from celebrity gossip to political campaigns, determining the best online tools can be daunting, especially for new practitioners. The list of resources below should go a long way in helping journalism students and journalists just starting their careers navigate the organizations, training institutes, and tool providers working on their behalf.

Since journalism programming in higher education is a really a topic unto itself, the focus of this compilation is on professional organizations, education, and training projects for both burgeoning and working journalists, new media and technology, and research and tools. There is some overlap between the categories.

But while some entries may fit under more than one category, the entities discussed have been categorized under the headings deemed most appropriate within the context of this article. Indeed, many of the organizations, institutes, and resource compendiums link to one another on their web pages. Although the list may not be comprehensive, a person visiting just one or two of the sites here should find more than enough links to other sites covering a variety of journalism-related subjects.

The headings begin with "Organization and Advocacy." Under this heading, readers will find professional societies, watchdog groups, and advocacy organizations actively involved in promoting press freedoms. The groups listed are both national and international in scope.

The "Education and Training" category features organizations dedicated not only to students but also to journalists seeking further professional development opportunities. Some of the training material is free, while other videos and tutorials are accessible to paying members.

The entries under "New Media and Technology" include sites where students and professionals can learn more about digital media and the impact technology has had on journalism.

Finally, the list concludes with "Research and Tools," where readers can find out where to go for tip sheets, data sets, research studies, and editing tools for journalists.

Overall, the amount of quality material freely available is remarkable, making it easier than ever for freelancers to research and write independently. The goal of this article is to narrow the field to the most credible sites on the web. Taken as a whole, the list should prove useful for reference librarians, students, and scholars, as well as practicing journalists.

\section{Organizations and advocacy}

- American Press Institute. Since 1946, the American Press Institute has been pursuing its mission of sustaining "a free press in the public interest." A nonadvocacy, nonprofit organization, its website offers up fact-checking

Hugh Burkhart is associate professor and reference librarian at the University of San Diego's Copley Library, email: hburkhart@sandiego.edu

(c) 2016 Hugh Burkhart 
resources and in-depth research reports, as well as news metrics for publishers. Content

from its

AMERICANPRESS morning institute newsletter is eas-

ily searched using keywords or by browsing the alphabetical topics list. This is an important site for new and seasoned journalists. Access: https://www.americanpressinstitute.org.

- Committee to Protect Journalists (CPJ). With a mandate to promote press freedom globally, CPJ reports on violence against journalists in repressive countries and takes action to stop repression. The focus of the resources available is on assistance and security for journalists. Visiting the site is a must for anyone seeking information before working abroad as a reporter. Access: https://www.cpj.org.

- International Consortium of Investigative Journalists (ICIJ). Launched as a project of the Center for Public Integrity, ICIJ "is a global network of more than 190 journalists in more than 65 countries who collaborate on in-depth investigative stories." The most notable projects include investigations concerning the Panama Papers and critiques of World Bank policies and practices. Stories are told in print and video format. There are also tools discussed in the "Resources" page, which covers such topics as researching using social media and how to improve online security. Access: https://www.icij.org.

- Investigative Reporters and Editors. This grassroots nonprofit, formed in 1975, was created as a forum for journalists to share story ideas, newsgathering, and news sources. The tip sheets in its resource center boast to having more than 3,500 guides for covering specific beats and stories. There is also a link to the National Institute for Computer-Assisted Reporting's fully searchable database (note that there are charges for many of the data sets themselves). With both jobs and resources centers, there is too much to list here and plenty for students and professionals. Access: https://www.ire.org.

- Pew Research Center: Journalism and Media. Journalism.org is the arm of this venerable fact tank. Here users will find articles on social media and journalism and trends in news media, as well as interactive content on a variety of topics, but especially concerned with media habits. Media students and scholars will likely find the searchable data sets on trends in the news media both useful and easy to use. Access: https://www. journalism.org.

- Reporters Committee for Freedom of the Press. With executive and steering committees composed of a number of wellknown journalists from both public and corporate media, this nonprofit is a leader in providing free access to legal resources "to protect the First Amendment and freedom of information rights of journalists," wherever U.S. law applies. Topics covered in its legal guide include understanding copyright law, reporter's privilege, and content regulation. Among the services offered through the site, the Freedom of Information Act guide is one of the most robust available for free. Access: https://www.rcfp.org.

- Reporters Without Borders. This Paris-based, nongovernmental organization has been a world leader in promoting and defending freedom of information since 1985. It produces the World Press Freedom Index, ranking 180 countries by freedom afforded to journalists. On the website, users can search its actions by geographic region, country, and publication type. The articles available will be useful for anyone interested in issues surrounding global information access. Access: https://rsf.org.

- Society of Professional Journalists (SPJ). For more than a century, the SPJ has worked to educate and advocate for current and future journalists. While members pay annual fees (with rates ranging according to one's chosen

plan), there is plenty

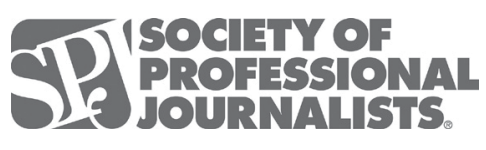
of free content on the site, including the SPJ magazine, Quill, a fully searchable career center, and freedom of information and ethics resources. More robust content, such as train- 
ing on demand videos, is available to paying members. Access: https://www.spj.org.

\section{Education and training}

- International Reporting Project

(IRP). This program was created to help journalists report on international issues that are under covered in the news media. IRP provides fellowships and travel grants and hosts events. International stories from 1998 to the present archived on its website are searchable by year. Current stories are searchable by location. This is an interesting resource for current news on topics that may not be receiving full coverage in the mainstream press. Access: http://internationalreportingproject.org.

- Knight Foundation. The Knight Foundation funds project's that advance the "goal of promoting informed and engaged communities to support a healthy democracy." It focuses on fostering innovation and community building. On its website, users can browse projects, read articles about the news industry, and apply for funding. Access: http://www.knightfoundation.org.

- Maynard Institute. This training institute's main interest is in promoting "accurate and nuanced" coverage of people of all cultures, particularly people of color. It funds reporting, editing, and management training programs. It also creates original content that works "to promote accurate portrayal of people of color in the media." The website features resources dealing with diversity in the media, as well as columns, features, and descriptions of the Maynard Institute's many programs. Access: http://mije.org.

- National Association of Hispanic Journalists (NAHJ). The goals of NAHJ include providing support for Hispanic journalists, promoting accurate treatment of Hispanics in the media, and furthering employment opportunities. Students can apply to scholarships and fellowships through the website, which also offers information on NAHJ's regional conferences and events, as well as a career center. Relevant news articles are also available. Access: http://nahj.org.
- Poynter Institute. The institute teaches a variety of journalism classes online, in newsrooms, and on its campus in St. Petersburg, Florida. Its online presence features articles

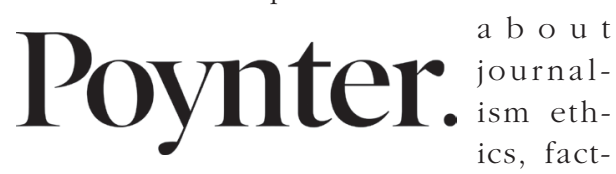

checking, and training, as well as commentary on current news media practices. Members have access to classes and job alerts. Access: http://www.poynter.org.

\section{New media and technology}

- Mashable. Launched in 2005, this digital media website is the go-to place for all things in tech, digital culture, and entertainment media. It is especially useful for tracking social media trends and technology news, and features channels broken down by subjects like business, entertainment, world, and lifestyle. There is also a complete archive of content dating back to the site's inception, as well as a job board. Access: http://mashable.com.

- Media Shift. Describing itself as the "premier destination for insight and analysis at the intersection of media and technology," MediaShift is an excellent source for stories about traditional media adapting to the networked world. In addition to the information on the site, MediaShift also hosts a weekly podcast and the DigitalEd online training series. There is also an up-to-date grants and funding section featuring a plethora of opportunities and awards for burgeoning journalists. Access: http://mediashift.org.

- Online News Association (ONA). While this nonprofit is an association of digital journalists, it is listed under the category here because of the unique content it offers. On its resources page, for instance, ONA offers a

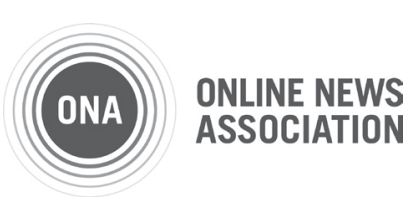

"Build Your Own Ethics Code" tool for digital journalists, as well as a career center. Paying ONA members can also access training webinars and networking opportunities. Access: http:// journalists.org. 


\section{Research and tools}

- Dart Center for Journalism and

Trauma. A project of the Columbia Journalism School, the Dart Center is focused on the reporting of violence and conflict, as well as providing information on the study of trauma. There are links to classroom resources and tips sheets, and articles categorized under such subjects as "Immigrant and Refugees," "Self-Care and Peer Support," and "War and Civil Conflict". The content is multimedia, with audio/video files and links to outside resources. Access: http:// dartcenter.org.

- Journalist's Resource. Based at the Shorenstein Center on Media, Politics, and Public Policy at Harvard, this project aims to bring research studies to the fore for journalists. Its searchable database of academic and government research contains more than 1,500 studies from a variety of fields, including economics, government, and international developments. There are also tip sheets, data resources, and even open source syllabi. In 2013, ALA named it one of the best free reference websites. Access: http://journalistsresource.org.

- Journalist's Toolbox. Presented by the Society of Profession Journalists (men- tioned earlier), this resource is exactly what it says it is. Several of the links listed on this site lead to many of the sites discussed in this article, but there is enough additional content to warrant a mention. A range of topics is covered, from video editing tools to campaign finance money trackers. These are listed by chronological entry and by discrete categories. The Toolbox's Twitter feed provides regular updates on new entries. Access: http://www.journaliststoolbox.org.

- Nieman Reports. This is the website and publication of Harvard's Nieman Foundation for Journalism. It is home to the Nieman Watchdog Project, detailing journalistic efforts to hold politicians and power brokers to account. Individual magazine issues dating back to 1947 are archived and freely available, including the most current issue. From the Nieman Reports page, users can also follow the links to the Nieman Fellowship, Lab, and Storyboard pages. Access: http://niemanreports. org.

\section{Note}

1. International Federation of Journalists Declaration of Principles on the Conduct of Journalists, www.ifj.org/about-ifj/ifj-code-of-principles/. $n$

\section{("Make more of these facilities!" continues from page 290)}

the need for a universal wireless solution so that both Apple and PC devices can be accommodated.

This first 18 months with ILS has been a success in a number of ways. The library added flexible teaching space, attracted a number of faculty back to the library, and made the library a stronger player and partner in the university's teaching enterprise. It also put the library at the forefront of technological change on the MSU campus. However, because of the issues that have arisen in managing the space and because this space is experimental, the library is in the process of analyzing usage statistics and evaluation data gathered since ILS opened. When that analysis is completed, we will be exploring ways to improve the space and the technology, increase use by faculty, and make its management more sustainable. This is entirely fitting as the space was never envisioned as static but always evolving to meet faculty needs and incorporate new technologies. With initiatives like this, we have the opportunity to increase the relevance of the physical library to faculty, reversing a trend inherent in the digital age.

\section{Notes}

1. Steven J. Bell, "Bringing Back the Faculty: The Evolution of the Faculty Commons in the Library," Library Issues: Briefings for Faculty and Administrators, 31 (2011): 1-4.

2. Ibid. $n$ 